\title{
PENYEDERHANAAN STRUKTUR BIROKRASI: SEBUAH TINJAUAN PERSPEKTIF TEORETIS DAN EMPIRIS PADA KEBIJAKAN PENGHAPUSAN ESELON III DAN IV
}

\section{SIMPLIFICATION OF THE BUREAUCRATIC STRUCTURE: AN OVERVIEW OF THEORETICAL AND EMPIRICAL PERSPECTIVES ON THE ELIMINATION POLICY OF $3^{\text {rd }}$ AND $4^{\text {th }}$ ECHELON}

\author{
(disubmit 13 Maret 2020, direvisi 15 Mei 2020, diterima 15 Juni 2020) \\ Mochamad Nurhestitunggal ${ }^{1}$ dan Muhlisin ${ }^{1,2}$ \\ ${ }^{1}$ Bappeda Provinsi Banten, Kawasan Pusat Pemerintahan Provinsi Banten \\ Jl. Syech Nawawi Al Bantani, Serang, Banten \\ ${ }^{2}$ Universitas Banten Jaya, Jl. Ciwaru II No. 73, Kota Serang, Banten \\ m.nurhesti@gmail.com
}

\begin{abstract}
ABSTRAK
Pelaksanaan grand design reformasi birokrasi, sampai dengan roadmap kedua, memang telah mencapai banyak hal. Namun demikian, tidak tercapainya indikator yang mencerminkan kapabilitas birokrasi, menunjukkan masih ada yang kurang dari pelaksanaan reformasi birokrasi di Indonesia. Masih terdapat permasalahan kelembagaan, budaya organisasi, profesionalisme SDM aparatur, tata laksana dan etika dalam pelayanan publik. Kajian ini sebagai upaya mengisi gap dalam literatur reformasi sektor publik di Indonesia, dari perspektif teoretis dan empiris, mengenai perlunya penyederhanaan struktur birokrasi yang dibahas melalui metode studi pustaka. Penyederhanaan struktur birokrasi, secara teroretis, diperlukan karena karakteristik yang terlalu birokratis sudah tidak sejalan dengan paradigma administrasi publik dan periode reformasi tata kelola sektor publik terkini, di samping karena desentralisasi. Secara empiris, penyederhanaan struktur birokrasi diperlukan karena menghambat peningkatan profesionalitas aparatur yang terlihat dari gejala bluffocracy dan consultocracy.
\end{abstract}

Kata kunci: reformasi birokrasi, desentralisasi, paradigma adminsistrasi publik, profesionalitas aparatur

\section{ABSTRACT}

The implementation of the grand design for bureaucratic reform, up to the second roadmap, has indeed achieved many things. However, the failure to achieve indicators that reflect the capabilities of the bureaucracy, shows that there is still something lacking in the implementation of bureaucratic reform in Indonesia. There are still institutional problems, organizational culture, professionalism of human resources, govern ance and ethics in public services. This study is an attempt to fill gaps in the literature on public sector reform in Indonesia, from a theoretical and empirical perspective, regarding the need to simplify the bureaucratic structure discussed through the literature study method. Simplification of the bureaucratic structure, from the theoretical perspectives, is necessary because too bureaucratic characteristics are not in line with the recent paradigm of public administration and the current period of public sector governance reform, in addition to decentralization. Empirically, simplification of the bureaucratic structure is needed because it impedes professionalism of the apparatus indicated by the symptoms of bluffocracy and consultocracy.

Keywords: bureaucratic reformation, decentralization, public administration paradigm apparatus professionalism 


\section{PENDAHULUAN}

Penyederhanaan birokrasi bukanlah isu baru dalam administrasi publik. Penyederhanaan birokrasi merupakan bagian dari reformasi tata kelola sektor publik yang lebih luas yang secara global mengacu pada empat bidang tematik yaitu: reformasi peran negara, reformasi fungsi sentral pemerintahan, reformasi terhadap akuntabilitas dan mekanisme pengawasan, serta reformasi birokrasi dan manajemen organisasi layanan publik (Turner, 2013).

Di Indonesia, reformasi birokrasi merupakan bagian dari pembaharuan menyeluruh di bidang ekonomi, politik, hukum, serta agama dan sosial budaya. Reformasi tersebut ditujukan untuk mewujudkan pemerintahan yang demokratis, dan mempercepat terwujudnya kesejahteraan rakyat.

Selain dalam rangka mengamankan demokrasi dan mendukung perekonomian, reformasi juga ditujukan untuk mewujudkan pemerintahan yang baik (good governance) (Polidano \& Hulme, 1999).

Selain reformasi birokrasi, reformasi administrasi publik di Indonesia juga ditujukan untuk mencapai tata pemerintahan yang baik. Melalui peningkatan profesionalisme aparatur negara, baik di pusat maupun di daerah, agar mampu mendukung keberhasilan pembangunan nasional. Sebagai acuan untuk mencapai tujuan penerapan reformasi birokrasi di Indonesia, yaitu membangun birokrasi pemerintahan yang profesional dan berintegritas tinggi, ditetapkan dokumen Grand Design Reformasi Birokrasi 2010-2025 dengan visi “Terwujudnya Pemerintahan Kelas Dunia". Operasionalisasi grand design reformasi birokrasi tersebut dituangkan dalam road map reformasi birokrasi yang milestones sasarannya sejalan dengan arah pembangunan nasional dalam RPJPN 2005-2025.

Banyak hal telah dicapai dari reformasi birokrasi di Indonesia, terlihat dari peningkatan capaian indikator kinerja yang mengukur keberhasilan penerapan reformasi birokrasi, diantaranya adalah peningkatan Indeks Integritas Kementerian/Lembaga $\quad(\mathrm{K} / \mathrm{L})$ dan Pemerintah Daerah (Komisi Pemberantasan Korupsi, 2018); peningkatan Indeks Integritas Pelayanan Publik di Instansi Pusat dan Daerah; peningkatan Indeks Reformasi Birokrasi, tingkat $\mathrm{K} / \mathrm{L}$ maupun pemerintah daerah serta kabupaten/kota (KemenPAN-RB, 2018, 2019); laporan Keuangan Pemerintah Pusat, sejak LKPP Tahun 2016, mendapatkan opini Wajar Tanpa Pengecualian (WTP) (Badan Pemeriksa Keuangan Republik Indonesia, 2017, 2019); peningkatan Indeks Kemudahan 
Berusaha 2020 (The World Bank, 2009, 2020); peningkatann Indeks Persepsi Korupsi (Transparency International, 2020); dan peningkatan Indeks Daya Saing Global.

Namun demikian, tidak semua indikator global yang mencerminkan kapabilitas birokrasi Indonesia mengalami kemajuan. Survei Opini Eksekutif 2017 menempatkan birokrasi pemerintah yang tidak efisien (World Economic Forum, 2017); Indeks Efektivitas Pemerintahan yang merupakan salah satu dimensi utama tata kelola pemerintah masih yang menggambarkan kemampuan pemerintah dalam mengambil kebijakan dan menyelenggarakan pelayanan publik secara efektif juga relatif sangat lambat, fluktuatif, dan bahkan tidak mencapai target tahun 2014 (Kaufmann \& Kraay, 2020).

Pelaksanaan reformasi birokrasi di Indonesia masih mengalami beberapa kelemahan. Studi oleh Turner, et. al. (2019) menyatakan bahwa program reformasi memang menunjukkan kemajuan dan mencatatkan beberapa pencapaian kinerja, namun perubahannya relatif kecil dan bersifat inkremental. Reformasi yang telah berhasil diimplementasikan sejauh ini tidak menghadirkan perubahan signifikan terhadap model dominan Old Public Administration.
Kelemahan mendasar dari reformasi birokrasi di Indonesia, menurut Turner, et al. (2019), adalah kegagalan dalam merombak manajemen SDM secara radikal, untuk menciptakan sistem berbasis merit dengan pegawai yang sangat berkualifikasi, berorientasi pada hasil, dan inovatif, dalam hubungan kerja yang lebih fleksibel, dan mendorong penggunaan kemampuan organisasi secara optimal (Turner. et al., 2019).

Upaya untuk mewujudkan manajemen SDM yang seperti itu, menurut Komarudin (2012), sebenarnya telah menjadi bahan kajian dan diskusi sejak tahun 2003-2004, melalui penataan kelembagaan yang disusun berdasarkan prinsip hemat struktur namun kaya fungsi, dengan lebih banyak unit/pemegang jabatan profesi/fungsional daripada jabatan struktural (Komarudin, 2012). Namun demikian, hingga akhir periode roadmap reformasi birokrasi kedua, kelembagaan dimaksud belum tercapai.

Selain masalah kelembagaan, baik di Pusat maupuan daerah, terdapat permasalahan lain yang berkaitan yaitu budaya organisasi, profesionalisme SDM aparatur, tata laksana dan etika dalam pelayanan publik (Bappenas, 2013)

Literatur tentang reformasi sektor publik di Indonesia sangat beragam dan multidisiplin. Banyak studi mengenai reformasi sektor publik di Indonesia dilihat 
dari berbagai perspektif, misalnya untuk memerangi korupsi (Kasim, 2013) meningkatkan akuntabilitas dengan mengadopsi akuntansi berbasis akrual (Jatmiko Wahyu Prabowo, Leung, \& Guthrie, 2017), perspektif teori budaya (Pratama, 2017), menjaga pertumbuhan ekonomi berkelanjutan (McLeod, 2005), desentralisasi (Nurprojo, 2014; Turner, et. al. 2009), dan masih banyak lagi. Namun demikian, belum ada analisis yang spesifik mengenai penyederhanaan struktur birokrasi. Kajian ini bertujuan mengisi gap, di dalam literatur reformasi sektor publik di Indonesia, dari perspektif tersebut yang secara spesifik akan menjawab pertanyaan, dari sisi teoretis dan empiris, mengenai mengapa struktur birokrasi Indonesia perlu disederhanakan.

\section{METODE PENELITIAN}

Kajian ini dilakukan dengan menggunakan studi kepustakaan (library research) melalui kajian berbagai referensi dan dokumen yang berkaitan dengan bidang kajian. Secara teoritis dikaji menggunakan teori kalsifikasi tipe-tipe administrasi publik menurut Ugyel (2014), yaitu patronasi, administrasi publik tradisional, NPM, serta model baru yang sedang berkembang. Sementara secara empiris diperoleh dari data-data terkini dari berbagai sumber terutama yang berkaitan dengan pengangkatan JFT, sistem merit, dan kompetensi pegawai baik pusat maupun daerah.

\section{HASIL DAN PEMBAHASAN \\ Profil Aparatur Sipil Negara (ASN) di Indonesia}

Kelembagaan birokrasi Indonesia begitu kompleks sehingga perlu disederhanakan. Jumlah ASN di Indonesia pada tahun 2019 adalah 4.189.121 orang (BKN, 2019). Sebanyak 22,77\% bertugas di Pemerintah Pusat dan $77,23 \%$ bertugas di Pemerintah Daerah. Jumlah aparatur yang menduduki Jabatan Fungsional Umum (JFU) dan Jabatan Fungsional Tertentu (JFT) berurut-turut sebanyak $38,46 \%$, dan 50,40\%. Secara rinci, jumlah ASN pada instansi pusat dan daerah dilihat dari jabatannya disajikan pada tabel 1 .

Tabel 1. Profil ASN Instansi Pusat dan Daerah Berdasarkan Jabatan

\begin{tabular}{lrrr}
\hline Jabatan ASN & Pusat & Daerah & Jumlah \\
\hline JPT Utama & 19 & & 19 \\
JPT Madya & 569 & 37 & 606 \\
JPT Pratama & 3.272 & 16.073 & 19.345 \\
Administrator & 17.153 & 83.602 & 100.755 \\
Pengawas & 61.017 & 270.086 & 331.103 \\
Eselon V & 12.698 & 2.191 & 14.889 \\
JFU & 511.266 & 1.099 .792 & 1.611 .058 \\
JFT & 347.737 & 1.763 .609 & 2.111 .346 \\
\hline Jumlah & 953.731 & 3.235 .390 & 4.189 .121 \\
\hline
\end{tabular}

Sumber: Diolah dari BKN (2019)

Berdasarkan Tabel I, ASN pusat dan daerah yang menduduki jabatan struktural adalah sejumlah 466.717, terdiri dari JPT Utama, JPT Madya, JPT Pratama, 
Administrator, Pengawas dan Eselon V. Dengan demikian, apabila akan dilakukan penyederhanaan birokrasi menjadi dua level eselon, maka diperlukan penyederhanaan terhadap 446.747 jabatan struktural Administrator, Pengawas dan Eselon V.

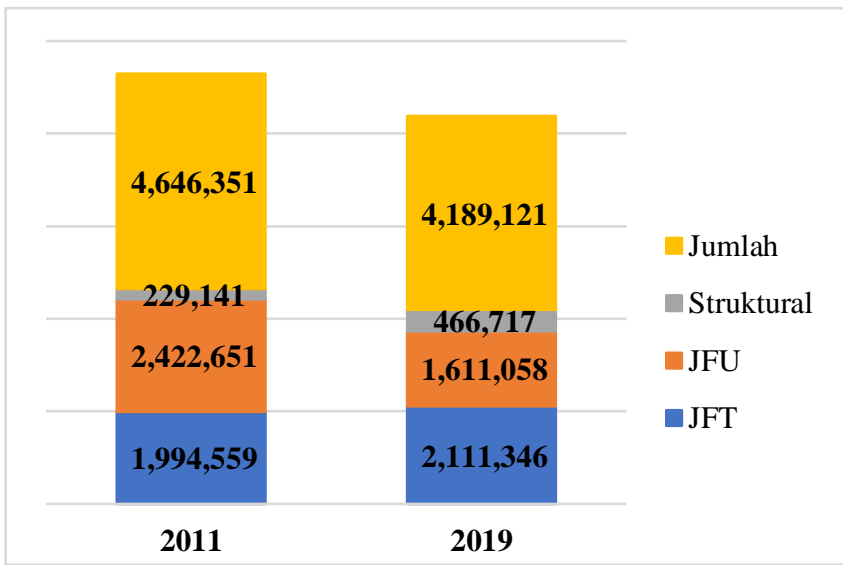

Gambar 1: Distribusi Jumlah ASN berdasarkan Jenis Jabatan, Tahun 2011 dan Tahun 2019.

Sumber: diolah dari BKN $(2011,2019)$

Selain itu, dapat dilihat bahwa jumlah Jabatan Fungsional Umum (JFU) lebih Banyak dibandingkan dengan Jabatan Fungsional Tertentu (JFT) (Gambar 1) yang didominasi oleh JFT Guru sebesar 69,94\% (Gambar 2). Dengan demikian JFT lain selain guru dan medis jumlahnya lebih kecil lagi. Ini menunjukkan bahwa JFT kurang berkembang.

Tidak berkembangnya JFT juga dapat dilihat dari proporsinya terhadap jumlah pegawai. Pada tahun 2011 jumlah JFT sebanyak 1.994 .559 (42,92\% dari jumlah 4.646.351 total ASN) pada tahun 2019 meningkat menjadi 2.111 .346 (50,40\% dari jumlah 4.189.121 total ASN), berarti terjadi peningkatan sebesar $5,86 \%$. Sementara itu pada tahun 2011 jabatan struktural sebanyak $229.141 \quad(4,93 \%$ dari jumlah 4.646.351 total ASN) pada tahun 2019 meningkat menjadi 466.717 (11,14\% dari jumlah 4.189.121 total ASN), berarti terjadi peningkatan sebesar $103,68 \%$.

Peningkatan yang sangat signifikan pada jabatan struktural dan kurang berkembangnya JFT, yang ditemukan oleh Bappenas sejak tahun 2011-2012, menunjukkan gejala proliferasi organisasi dan mengukuhkan Parkinson's Law tentang birokrasi (Bappenas, 2013). Padahal untuk mempercepat terwujudnya organisasi birokrasi yang "miskin struktur, kaya fungsi" hasil evaluasi kebijakan Reformasi Birokrasi, dengan memperbanyak jabatan fungsional" (Bappenas, 2013).

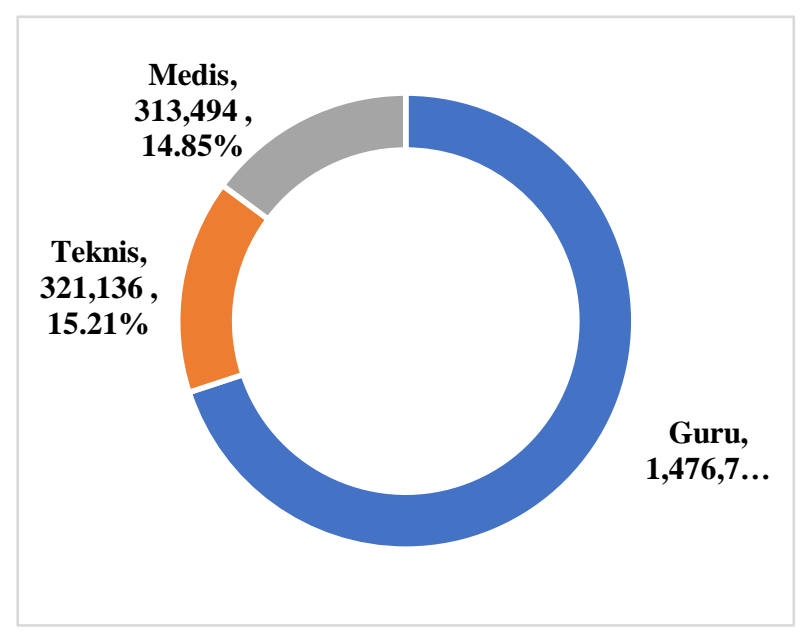

Gambar 2: Jumlah ASN berdasarkan JFT Tahun 2019. Sumber: Diolah dari BKN (2019) 
Kurang berkembangnya JFT mengindikasikan bahwa kebijakan dan arah reformasi birokrasi di bidang kelembagaan, untuk menciptakan birokrasi yang ramping struktur dan kaya fungsi, efisien, dan efektif, lebih banyak diisi jabatan-jabatan fungsional yang mengedepankan kompetensi dan profesionalitas dalam pelaksanaan tugasnya, secara empiris tidak terwujud.

Sekalipun secara proporsi meningkat, komposisi JFT tidak ideal. Dari sejumlah 2.111.346 pegawai yang menduduki JFT pada tahun 2019, 69,94\% adalah guru, $14,85 \%$ adalah tenaga medis, dan JFT teknis $15,21 \%$. Selain komposisi, sebarannya juga tidak ideal. JFT Teknis di pusat lebih banyak daripada di daerah. Di instansi pusat, dari 347.737 JFT, 37,17\% adalah guru, $6,37 \%$ adalah tenaga medis, dan JFT teknis $56.46 \%$. Sedangkan di daerah, dari 1.763.609 JFT, 76,40\% adalah guru, $16,52 \%$ adalah tenaga medis, sedangkan JFT teknis hanya 7,08\%. Secara rinci komposisi dan sebaran JFT disajikan pada gambar 2 dan 3.

Dilihat dari komposisinya, dari 25 rumpun jabatan fungsional yang ada, yang lebih berkembang adalah rumpun Pendidikan dan rumpun Kesehatan. Sedangkan secara sebaran, terlihat bahwa setelah desentralisasi, di mana penyelenggaraan sebagian besar urusan pemerintahan dilakukan oleh daerah, JFT teknis di daerah justru tidak berkembang.

Turner et al. (2009) menyebut praktik manajemen SDM di daerah sebagai "the forgotten dimension of decentralisation" yang lebih berorientasi pada kontrol, tata tertib dan loyalitas, daripada pada peningkatan kinerja (Turner et al., 2009). Karena cara ASN diorganisasikan di tingkat lokal memiliki dampak signifikan pada pencapaian tujuan desentralisasi (Seddon \& De Tommaso, 1999), tidak berkembangnya JFT teknis yang yang memiliki spesialisasi pada kompetensi tertentu, menunjukkan arsitektur manajemen SDM di daerah yang tidak memiliki orientasi strategis dan tidak ditujukan untuk membangun kompetensi dengan fokus perhatian pada kebutuhan spesifik pemerintah daerah.

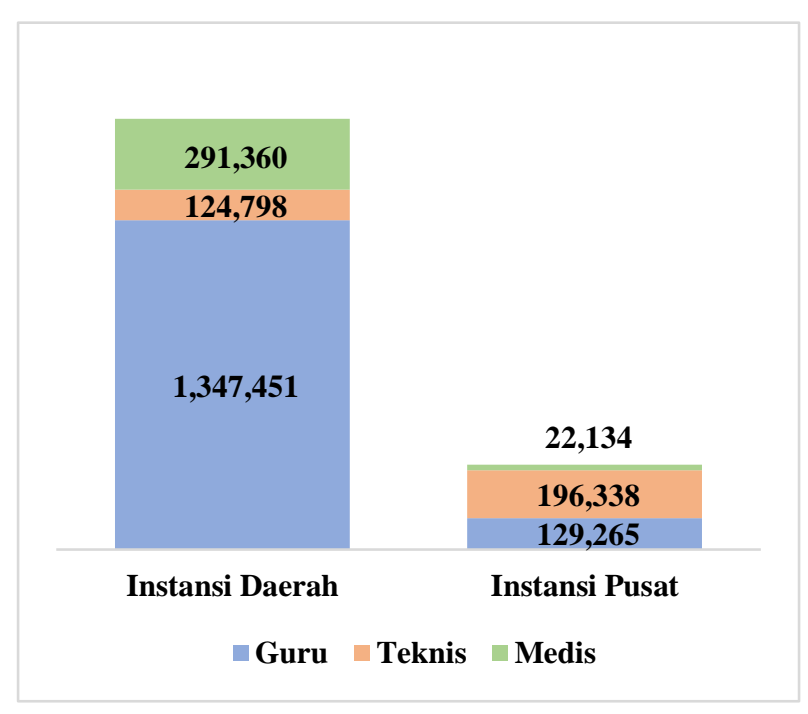

Gambar 3: JFT di Instansi Daerah dan Instansi Pusat Tahun 2019 Sumber: Diolah dari BKN (2019).

$$
\text { Dengan demikian, Tidak }
$$
berkembangnya JFT, terutama JFT teknis, 
Jurnal Kebijakan Pembangunan Daerah, Vol.4, No.1, Juni 2020, Hal. 1 - 20

p-ISSN: 2597-4971, e-ISSN: 2685-0079

menghambat pembangunan budaya birokrasi yang profesional.

\section{Penghapusan Eselon IV dan III dalam Perspektif Teoritis}

Secara teoritis, penyederhanaan birokrasi menjadi dua level eselon diperlukan karena karakteristik yang terlalu birokratis sudah tidak sejalan dengan paradigma administrasi publik dan periode reformasi tata kelola sektor publik terkini. Menggunakan gagasan paradigma yang dilakukan oleh para ahli administrasi publik, Ugyel (2014) mengklasifikasikan administrasi publik yang ideal ke dalam empat tipe: patronasi, administrasi publik tradisional, NPM, serta model baru yang sedang berkembang. Karakter yang birokratis merupakan ciri dari administrasi publik tradisional, sedangkan untuk model mutakhir, lebih menekankan pada collaborative governance (Ugyel, 2014).

Dilihat dari periode reformasi administrasi publik, baik tiga gelombang reformasi sektor publik menurut Baimyrzaeva (2012b) maupun enam kelompok reformasi menurut McCourt (2018), fokus dan ruang lingkup reformasi sektor publik sejak akhir tahun 1990-an adalah pada bagaimana membuat pemerintah lebih responsif terhadap warga negara melalui transformasi institusi pemerintah melalui penguatan dan partisipasi dari sektor swasta dan masyarakat sipil.

Administrasi publik 'Weber' yang birokratis, diperlukan untuk modernisasi dan stabilitasi pada masa pasca kemerdekaan di Asia Selatan dan SubSahara Afrika atau tahun 1950 sampai dengan 1960-an, dan telah digantikan oleh paradigma lain seperti desentralisasi, NPM, dan reformasi "Bottom-up" (Baimyrzaeva, 2012b; McCourt, 2018). Birokrasi Weberian, dengan hubungan hierarki yang diformalkan secara ketat antara atasan dengan bawahan dan kepatuhan terhadap aturan tertulis, menurut NPM, tidak dapat menyelenggarakan negara modern secara efektif dalam menyediakan layanan yang efisien dengan cara yang responsif dan bertanggung jawab (Clegg, 1990; Osborne \& Gaebler, 1992). NPM kemudian menjadi paradigma global yang menggantikan model administrasi publik tradisional.

Namun demikian, mengadopsi praktik yang dikembangkan di sektor swasta dan menerapkannya di sektor publik menuai kritik karena mengaburkan perbedaan antara sektor publik dan swasta. NPM gagal memenuhi tujuannya untuk menghasilkan pemerintah yang bekerja lebih baik dengan biaya lebih rendah (Hood \& Dixon, 2015), karena tidak mengapresiasi konteks di mana NPM beroperasi yaitu wilayah administrasi politik (Du Gay, 2000; Suleiman, 2013). 
Kelemahan utama NPM adalah hanya melihat pohon managerial di dalam hutan politik, konstitusional dan pemerintahan (Byrkjeflot, du Gay, \& Greve, 2018), sementara reformasi administrasi publik bukan hanya mengenai permasalahan manajemen operasi, biaya dan respons jangka pendek, namun lebih kepada isu-isu yang bersifat konstitusional, karena mempengaruhi fondasi kehidupan politik dan kapasitas negara (Dunleavy \& Hood, 1994). Sehingga dalam iklim reformasi dalam administrasi publik terkini, terdapat tuntutan untuk mencari alternatif selain NPM.

Pada Tahun 2004, Christopher Pollitt dan Geert Bouckaert memperkenalkan teori "Neo-Weberian State" (NWS) ke dalam diskusi internasional tentang reformasi manajemen publik. NWS menggarisbawahi pentingnya negara, yang bersifat konstitutif, sebagai tempat di mana politik demokratis berlangsung, dan birokrasi sebagai bentuk atau mekanisme politik administrasi inti (Pollitt \& Bouckaert, 2004).

Mengenai reformasi tata kelola, Pollitt dan Bouckaert membagi negaranegara ke dalam the "maintainers", the "modernizers", dan the "marketizers", dengan dua kelompok inti yaitu Anglo American NPM marketizers dan the continental European modernizers (Pollitt \& Bouckaert, 2004). Model reformasi
Eropa kontinental inilah yang diklasifikasikan oleh Pollitt dan Bouckaert sebagai "NWS".

NWS mengikuti konsep birokrasi Weber sebagai upaya untuk membuat birokrasi tradisional Weber menjadi lebih profesional, efisien, dan responsif kepada warga negara dengan tambahan elemen baru. Tambahan elemen baru tersebut adalah pertama, peralihan dari orientasi internal pada aturan birokrasi menuju orientasi eksternal pada pemenuhan kebutuhan dan keinginan warga melalui penciptaan budaya profesional terhadap kualitas dan layanan; kedua, melengkapi peran demokrasi perwakilan dengan serangkaian perangkat untuk konsultasi dengan, dan representasi langsung dari pendapat warga negara; ketiga, modernisasi undang-undang yang relevan untuk mendorong orientasi yang lebih besar pada pencapaian hasil daripada sekadar ketaatan pada prosedur melalui pergeseran keseimbangan dari pengendalian ex-ante ke ex-post; serta keempat, profesionalisasi layanan publik agar birokrat tidak hanya menjadi ahli dalam peraturan yang relevan dengan bidang kegiatannya, tetapi juga seorang manajer profesional yang berorientasi untuk memenuhi kebutuhan warga negara (Pollitt \& Bouckaert, 2011). Dalam NWS, hal-hal yang penting dari birokrasi tetap menjadi landasan 
administrasi publik dengan beberapa modernisasi.

Salah satu upaya melakukan modernisasi terhadap birokrasi Weberian, di bidang organisasi, adalah melalui penyederhanaan struktur dan proses birokrasi dengan "to abolish steep hierarchies" atau "dismantling of levels of hierarchy" (Kuhlmann, Bogumil, \& Grohs, 2008).

NPM memberi kritik terhadap birokrasi Weberian, salah satunya adalah bahwa birokrasi tradisional yang hierarkis dan terpusat, yang dirancang pada tahun 1930-an atau 1940-an, tidak berfungsi dengan baik dalam masyarakat dan ekonomi yang cepat berubah, kaya informasi, dan intensif pengetahuan pada tahun 1990-an (Osborne \& Gaebler, 1992).

Dengan tambahan elemen baru, birokrasi tradisional bergaya Weberian sekarang dapat bergerak, tanpa kerugian yang signifikan, ke jenis organisasi baru yang modern dan memperbaiki semua kekurangan di masa lalu. Terhadap birokrasi Indonesia, yang menurut Turner et al. (2019) masih dominan dengan kombinasi antara karakteristik "Old Public Administration dan Patronage" (Turner et al., 2019). Terdapat bukti "jejak NWS" dalam upaya yang dilakukan oleh pemerintah Indonesia untuk memodernisasi birokrasi rasional Weberian bercorak patrimonial yang ada sekarang (Gaus,
Sultan, \& Basri, 2017) dan penyederhanaan birokrasi menjadi hanya dua level eselon perlu dilakukan.

Selain karena karakteristik yang terlalu birokratis sudah tidak sejalan dengan paradigma administrasi publik dan periode reformasi tata kelola sektor publik terkini, secara teoretis, penyederhanaan birokrasi menjadi hanya dua level eselon juga diperlukan karena desentralisasi.

Dengan adanya pembagian urusan pemerintahan antara pemerintah pusat, pemerintah provinsi dan pemerintah kabupaten/kota, sehingga masing-masing mempunyai urusan pemerintahan sendirisendiri "yang sifatnya tidak hierarki”, maka struktur yang lebih datar dapat diterapkan. Ini sejalan dengan pendapat Downs (1964), yang menyatakan bahwa hierarki "datar" umumnya dikaitkan dengan desentralisasi, sedangkan hierarki "tinggi" adalah tipikal dari biro yang lebih tersentralisasi.

Dengan desentralisasi hierarki "datar" lebih sesuai untuk diterapkan. Karena fungsi suatu organisasi relatif sederhana atau jelas, lingkungan yang stabil, staf yang relatif tidak spesifik, teknik internal yang stabil, dan keanggotaan yang homogeny (Downs, 1964). Dalam konteks Indonesia, di mana organisasi di daerah tidak hierarki dengan kementerian di pusat, sehingga tidak perlu jumlah eselon yang banyak antara perumus kebijakan di pusat dengan pelaksana di lapangan, maka struktur 
piramidal birokrasi yang tinggi dapat disederhanakan.

Merasionalisasi struktur birokrasi telah menjadi salah satu tantangan terbesar yang dihadapi dalam reformasi birokrasi di Indonesia. Desentralisasi tidak membuat struktur birokrasi kementerian dan lembaga menjadi right-size, meskipun sebagian besar fungsi telah diserahkan ke pemerintah di tingkat sub-nasional dan lokal (Prasojo, 2009).

Right-sizing yang belum tepat setelah desentralisasi ini dikonfirmasi oleh BKN (2016), yang menemukan bahwa jumlah ASN yang bekerja di instansi Pusat masih mencapai $21 \%$, dari yang seharusnya cukup $10 \%$ mengingat tugas fungsinya hanya sebagai pengendali kebijakan karena tugas utama pelayanan publik ada di instansi Daerah (BKN, 2016). Namun demikian, studi tidak menemukan bahwa desentralisasi menyebabkan pengurangan lapangan kerja sektor publik (Alonso, Clifton, \& Díaz-Fuentes, 2015), sehingga pengurangan dapat dilakukan pada hieraki strukturnya yang terlalu tinggi.

\section{Penghapusan Eselon IV dan III dalam Perspektif Empiris}

Penghapusan unit eselon IV dan eselon III, pada unsur pelaksana tertentu, dengan mengoptimalkan para pegawai yang menduduki jabatan tersebut ke dalam jabatan fungsional, juga merupakan salah satu kebijakan mendasar Kementerian Pendayagunaan Aparatur Negara dan Reformasi Birokrasi (KemenPAN-RB) di bidang kelembagaan (Komarudin, 2012). Namun demikian, hingga akhir periode kedua roadmap reformasi birokrasi, penghapusan struktur tersebut tidak terwujud.

Oleh karenanya, ketika upaya untuk mengurangi size birokrasi Indonesia hanya membuat sedikit kemajuan, dengan hanya ada sedikit stabilisasi angka melalui pembatasan rekrutmen (Turner et al., 2019). Selain itu, juga relatif sulit untuk menentukan ukuran tentang berapa jumlah ASN yang ideal dalam menyelenggarakan tugas-tugas pemerintahan dan pembangunan (Bappenas, 2013).

Upaya right-sizing dapat dilakukan pada struktur hierarki menjadi piramida yang lebih datar. Hal ini perlu karena perubahan struktur formal memiliki dampak yang jauh lebih kuat pada reformasi gaya manajerial (Gualmini, 2008; Park, 2019). Selain itu, Diefenbach and Sillince (2011) menyimpulkan bahwa struktur hierarki formal berkaitan erat dengan proses pengambilan keputusan dan alokasi sumber daya, yang apabila dipadukan dengan aturan formal seperti rekrutmen berdasarkan sistem merit, dapat menunjang profesionalisme. Faktor profesionalisme inilah yang menjadi 
pertimbangan empiris mengapa hierarki birokrasi perlu disederhanakan.

Hierarki birokrasi perlu disederhanakan, karena secara empiris menghambat peningkatan profesionalitas aparatur. Reformasi birokrasi Indonesia ditujukan untuk meningkatkan profesionalisme aparatur negara dan untuk mewujudkan tata pemerintahan yang baik.

Untuk meningkatkan profesionalisme, aspek ke empat dari sembilan aspek percepatan reformasi birokrasi dalam Road Map Reformasi Birokrasi 2010-2014, adalah profesionalisasi ASN, yang salah satu rencana aksinya adalah Penguatan Jabatan Fungsional. Penguatan jabatan fungsional tersebut dilakukan melalui penambahan jumlah jabatan fungsional, penetapan pola karier, peningkatan kompetensi, dan peningkatan kesejahteraan (KemenPANRB, 2012a).

Sejak moratorium penerimaan Calon ASN Tahun 2011, penyusunan kebutuhan formasi dan pengadaan Calon ASN diarahkan secara selektif, yang salah satunya untuk memenuhi JFT. Namun demikian, karena struktur hierarki yang tinggi, sebagian besar instansi pemerintah, terutama di daerah, tidak memberdayakan JFT secara maksimal, sehingga jabatan struktural masih menjadi jabatan favorit (Bappenas, 2013).
Pengangkatan ke dalam JFT cenderung hanya sebagai penampungan bagi ASN yang tidak mendapatkan posisi dalam jabatan struktural, atau untuk memperpanjang batas usia pension. Sebagai akibatnya, seperti sebuah zero sum game, meskipun menjadi salah satu rencana aksi untuk profesionalisasi ASN, JFT menjadi tidak berkembang.

Untuk menghasilkan ASN yang profesional, kebijakan dan manajemen ASN diselenggarakan berdasarkan sistem merit. Dengan sistem merit, maka pengembangan karier, pengembangan kompetensi, pola karier, mutasi, dan promosi dilakukan berdasarkan pada kualifikasi, kompetensi, dan kinerja ASN secara adil dan wajar. Apabila pada JFT standar kualitas dan profesionalitas dijamin oleh instansi pembina dengan kompetensi yang terstandarisasi, maka pada jabatan struktural, terutama eselon III, IV dan V di daerah, sistem merit belum sepenuhnya diterapkan. Terlepas dari adanya champions di beberapa daerah yang telah menerapkan sistem merit karena faktor leadership (Prasojo \& Holidin, 2018), promosi, pemindahan dan pemberhentian dalam dan dari jabatan struktural, terutama eselon III, IV, dan V. Penerapan sistem merit di daerah, cenderung tidak obyektif dan tidak melalui seleksi atau evaluasi yang obyektif dan rasional. 
Sistem merit lebih didominasi oleh adanya "politisasi birokrasi" (BKN, 2018; Nurprojo, 2014; Rewansyah, 2011), sekalipun terdapat amanat kepada seluruh $\mathrm{K} / \mathrm{L}$ dan pemerintah daerah untuk menerapkan pengisian lowongan jabatan struktural dengan sistem merit dan terbuka (KemenPAN-RB, 2012b, 2014). Dengan politisasi birokrasi, terbentuk jaringan patronase yang kuat yang lebih menilai loyalitas dibandingkan kinerja (Turner, 2013). Sebagai akibatnya, terjadi missmatch antara kompetensi dengan kualifikasi jabatan.

Kesenjangan kompetensi dengan kualifikasi jabatan mengakibatkan kesenjangan kemampuan untuk melakukan tugas dan tanggung jawab jabatan. Pemetaan kompetensi dan potensi terhadap 2.670 Administrator (eselon III) dari 396 instansi Pemerintah Daerah, yang berasal dari 26 Pemerintah Provinsi, 75 Pemerintah Kota, dan 295 Kabupaten, menemukan bahwa hanya $7,04 \%$ yang memiliki potensi dan kompetensi tinggi (BKN, 2017).

Dua kompetensi terendah pada administrator adalah PerencanaanPengorganisasian (Planning-Organizing) dan Orientasi pada Hasil (Driving for Results), di samping Team Leadership, dan Conflict Management (BKN, 2017). Rendahnya kompetensi planningorganizing dan driving for results, yang justru berkaitan erat dengan proses pengambilan keputusan dan alokasi sumber daya. Hal ini mengindikasikan rendahnya kompetensi manajerial yang lain seperti fleksibilitas berpikir, inovasi, berpikir analitis, berpikir konseptual, serta kepemimpinan tim (KemenPAN-RB, 2017). Rendahnya kompetensi planningorganizing dan driving for results juga mencerminkan rendahnya kompetensi spesifik yang berkaitan dengan bidang teknis jabatan sehingga terjadi gejala bluffocracy dan consultocracy yang mengakibatkan birokrasi biaya tinggi.

Bluffocracy dan consultocracy merupakan gejala yang mengindikasikan masalah inexpertise di birokrasi. Bluffocracy adalah penyelenggaraan birokrasi oleh para "bluffer", orang-orang yang pengetahuannya melebar satu mil, tetapi kedalamannya hanya satu inci; yang memahami topik secara umum, tetapi tidak mau tahu dengan hal-hal spesifik (Ball \& Greenway, 2018). Rendahnya kompetensi manajerial inti dan kompetensi spesifik yang berkaitan dengan bidang teknis jabatan, berdasarkan hasil pemetaan kompetensi dan potensi terhadap administrator, membuktikan gejala bluffocracy.

Sementara itu, consultocracy merupakan kecenderungan peningkatan peran konsultan manajemen swasta dalam perumusan kebijakan sektor publik (Hood \& Jackson, 1991). Terminologi 
consultocracy menjadi popular ketika Saint-Martin (1998) menemukan peningkatan belanja publik untuk jasa konsultansi eksternal yang sangat signifikan dalam satu dekade, 300\% di Inggris dan $400 \%$ di Kanada. Bluffocracy dan belanja jasa konsultansi dalam jumlah yang signifikan juga terjadi di Indonesia, terutama di Pemerintah Daerah.

Walaupun terdapat alasan yang sah untuk menggunakan jasa konsultan eksternal guna memberikan kompetensi dan keahlian yang tidak dapat diproduksi sendiri, namun terdapat dampak problematis dari meningkatnya peran konsultan terhadap administrasi publik. Salah satu konsekuensi yang paling mendasar adalah melemahnya akuntabilitas.

Ketika birokrasi mengontrak jasa konsultansi, maka setidaknya sebagian dari tanggung jawab mengenai hasilnya diserahkan kepada pihak konsultan. Pihak pemberi kontrak dapat menyalahkan konsultan untuk hasil atau kelalaian yang tidak diinginkan kepada atasan mereka atau pihak lain yang berkepentingan (Ylönen \& Kuusela, 2019). Hal ini mendistorsi konsep akuntabilitas, karena melampaui peran keahlian dan teknokrasi yang lebih besar dalam politik, sehingga "cenderung menghilangkan administrasi publik dari politik, dan dari pengawasan publik" (Saint-Martin, 1998). Padahal, semestinya birokasi bertanggung jawab terhadap pelaksanaan kebijakan dan program, consultocracy mendistorsi konsep tersebut. Selain mendistorsi konsep akuntabilitas, consultocracy juga tidak sesuai dengan asas akuntabilitas berorientasi pada hasil dalam pengelolaan keuangan negara. Ketika keuangan negara wajib dikelola secara efisien, ekonomis, efektif, transparan, dan bertanggung jawab, dengan memperhatikan rasa keadilan dan kepatutan maka consultocracy merupakan double burden dan birokrasi biaya tinggi.

Berdasarkan studi (Angkasah, Adolf, \& Wibowo, 2017; Harun, Mir, Carter, \& An, 2019; Rewansyah, 2011; Turner et al., 2019), keuangan negara, terutama di daerah, sudah harus menanggung beban belanja pegawai dalam proporsi yang signifikan.

Mengenai consultocracy, Ylönen dan Kuusela (2019) menyimpulkan, apabila organisasi sektor publik dapat mengembangkan alternatif yang lebih baik, yang berangkat dari karakteristik demokrasi dan etos publik, meminta solusi sektor publik dari konsultan eksternal akan menjadi kurang dibutuhkan. Menghapus struktur managerial birokrasi yang tinggi dan memperbanyak JFT dapat menjadi solusi, karena mendorong ASN untuk bekerja dengan keahlian dan/atau ketrampilan spesifik tertentu sehingga 
dapat lebih profesional, dan mengurangi

bluffocracy serta consultocracy.

\section{KESIMPULAN DAN REKOMENDASI}

\section{Kesimpulan}

Pelaksanaan grand design reformasi birokrasi, sampai dengan roadmap kedua, memang telah mencapai banyak hal. Namun demikian, tidak tercapainya indikator yang mencerminkan kapabilitas birokrasi, menunjukkan masih ada yang kurang dari pelaksanaan reformasi birokrasi di Indonesia. Masih terdapat permasalahan kelembagaan, budaya organisasi, profesionalisme SDM aparatur, tata laksana dan etika dalam pelayanan publik. Reformasi birokrasi memang telah menghasilkan "small wins" yang mengarah pada kemajuan positif dalam administrasi publik, namun belum cukup untuk merubah hegemoni model Old Public ManagementPatronage pada birokrasi Indonesia. Penyederhanaan birokrasi melalui penyederhanaan eselonisasi menjadi dua level, sebagai salah satu agenda prioritas pembangunan lima tahun ke depan, dapat menjadi upaya memenuhi tenggat waktu untuk mencapai visi "Pemerintahan Kelas Dunia" dalam Grand Design Reformasi Birokrasi 2010-2025.

Penyederhanaan struktur birokrasi, secara teroretis, diperlukan karena karakteristik yang terlalu birokratis sudah tidak sejalan dengan paradigma administrasi publik dan periode reformasi tata kelola sektor publik terkini, di samping karena desentralisasi.

Secara empiris, penyederhanaan struktur birokrasi diperlukan karena menghambat peningkatan profesionalitas aparatur yang terlihat dari gejala bluffocracy dan consultocracy. Melalui restrukturisasi, sebagai bagian dari reformasi yang komprehensif terhadap birokrasi Indonesia, maka harapan agar tugas birokrasi dalam making program benefit delivered, sehingga masyarakat menikmati pelayanan, menikmati hasil pembangunan.

\section{Rekomendasi}

Beberapa rekomendasi yang berkaitan dengan penghapusan Eselon III dan IV:

1. Momentum penghapusan struktur eselon III dan IV semestinya menjadi bagian dari reformasi yang komprehensif terhadap birokrasi Indonesia, yaitu dalam rangka mewujudkan visi jangka panjang yang koheren dari reformasi administrasi yang menyeluruh.

2. Penyederhanaan struktur birokrasi harus dilakukan sekarang untuk mewujudkan birokrasi berkelas dunia.

3. Fokus bahwa tujuan restrukturisasi adalah untuk meningkatkan kinerja 
birokrasi, terutama untuk meningkatkan

kualitas pelayanan publik.

4. Perlu dukungan dan komitmen dari

semua pihak dalam melaksanakan

restrukturisasi birokrasi

\section{DAFTAR PUSTAKA}

Alonso, J. M., Clifton, J., \& Díaz-Fuentes, D. (2015). Did New Public Management Matter? An empirical analysis of the outsourcing and decentralization effects on public sector size. Public Management Review, 17(5), 643-660. Retrieved from

https://doi.org/10.1080/14719037.2 013.822532 . doi:10.1080/14719037.2013.82253 2

Angkasah, L., Adolf, H., \& Wibowo, G. D. H. (2017). Bureaucratic Reform in the Perspective of State Administration Law. Mediterranean Journal of Social Sciences, 8(5-1), 35-41.

Ball, J., \& Greenway, A. (2018). The rise of the bluffocracy: Britain has become hooked on a culture of inexpertise. Retrieved from https://www.spectator.co.uk/2018/0 8/the-bluffocracy-how-britainended-up-being-run-by-eloquentchancers

Bappenas. (2013). Evaluasi Kebijakan Reformasi Birokrasi. Retrieved from Jakarta: https://www.bappenas.go.id/files/e kps/2013/4.Evaluasi\%20Kebijakan \%20Reformasi\%20Birokrasi.pdf

Badan Pemeriksa Keuangan Republik Indonesia. (2017). BPK Berikan Opini WTP atas LKPP Tahun 2016. Retrieved from https://www.bpk.go.id/news/bpk- berikan-opini-wtp-atas-lkpp-tahun$\underline{2016}$

Badan Pemeriksa Keuangan Republik Indonesia. (2019). BPK Kembali Memberikan Opini WTP atas Laporan Keuangan Pemerintah Pusat Tahun 2018. Retrieved from https://www.bpk.go.id/news/bpkkembali-memberikan-opini-wtpatas-laporan-keuangan-pemerintahpusat-tahun-2018

BKN. (2011). Profil Statistik Pegawai Negeri Sipil. Jakarta Retrieved from http://bkn.go.id/in/profil/unitkerja/inka/direktorat-pengolahandata/profil-statistik-ASN/distribusiASNberdasarkan-kelompok-jenisjabatan-dan-jenis-kelamin-1oktober-2011.html

BKN. (2016). Civil Apparatus Policy Brief: Rasionalisasi Kebutuhan dan Distribusi ASN Nasional. Jakarta Retrieved from https://www.bkn.go.id/wpcontent/uploads/2014/06/PolicyBrief-Distribusi-ASN20-102016.pdf

BKN. (2017). Hasil Talent Pool 2017: 4,17 $\%$ Pejabat Tinggi Birokrasi Berkompetensi dan Potensi Tinggi. Retrieved from https://www.bkn.go.id/berita/hasiltalent-pool-2017-417-pejabattinggi-birokrasi-berkompetensidan-potensi-tinggi

BKN. (2018). Civil Apparatus Policy Brief:

Dikotomi Sistem Merit dan Politisasi Birokrasi dalam Pengangkatan Jabatan ASN. Jakarta Retrieved from https://www.bkn.go.id/wpcontent/uploads/2014/06/05.PolicyBrief-Mei-2018.pdf

BKN. (2019). Buku Statistik Pegawai Negeri Sipil. Jakarta Retrieved from https://www.bkn.go.id/wpcontent/uploads/2020/03/bukustatistik-2.pdf 
Byrkjeflot, H., du Gay, P., \& Greve, C. (2018). What is the 'Neo-Weberian State'as a Regime of Public Administration? In The Palgrave handbook of public administration and management in Europe (pp. 991-1009): Springer.

Clegg, S. (1990). Modern organizations: Organization studies in the postmodern world: Sage.

Diefenbach, T., \& Sillince, J. A. A. (2011). Formal and Informal Hierarchy in Different Types of Organization. Organization Studies, 32(11), 15151537. Retrieved from https://journals.sagepub.com/doi/ab s/10.1177/0170840611421254. doi:10.1177/0170840611421254

Downs, A. (1964). Inside Bureaucracy. RAND Corporation paper series, 2963. Retrieved from https://www.rand.org/content/dam/ rand/pubs/papers/2008/P2963.pdf.

Du Gay, P. (2000). In praise of bureaucracy: Weber-organizationethics: Sage.

Dunleavy, P., \& Hood, C. (1994). From old public administration to new public management. Public money \& management, 14(3), 9-16.

Gaus, N., Sultan, S., \& Basri, M. (2017). State Bureaucracy in Indonesia and its Reforms: An Overview. International Journal of Public Administration, 40(8), 658-669. Retrieved from https://doi.org/10.1080/01900692.2 016.1186179 .

doi:10.1080/01900692.2016.11861 79

Greve, C., Ejersbo, N., Lægreid, P., \& Rykkja, L. H. (2020). Unpacking Nordic Administrative Reforms: Agile and Adaptive Governments. International Journal of Public Administration, 43(8), 697-710. Retrieved

from https://doi.org/10.1080/01900692.2 019.1645688 . doi:10.1080/01900692.2019.16456 88

Gualmini, E. (2008). Restructuring Weberian Bureaucracy: Comparing Managerial Reforms in Europe and the United States. Public Administration, $\quad 86(1), \quad 75-94$. Retrieved from https://onlinelibrary.wiley.com/doi/ abs/10.1111/j.14679299.2007.00691.x. doi:10.1111/j.14679299.2007.00691.x

Harun, H., Mir, M., Carter, D., \& An, Y. (2019). Examining the unintended outcomes of NPM reforms in Indonesia. Public money \& management, 39(2), 86-94.

Hood, C., \& Dixon, R. (2015). A government that worked better and cost less?: Evaluating three decades of reform and change in UK central Government: OUP Oxford.

Hood, C., \& Jackson, M. W. (1991). Administrative argument: Dartmouth Publishing Group.

Jatmiko Wahyu Prabowo, T., Leung, P., \& Guthrie, J. (2017). Reforms in public sector accounting and budgeting in Indonesia (20032015): confusions in implementation. Journal of Public Budgeting, Accounting \&amp; Financial Management, 29(1), 104137. Retrieved from https://doi.org/10.1108/JPBAFM29-01-2017-B005. doi:10.1108/JPBAFM-29-01-2017B005

Kasim, A. (2013). Bureaucratic Reform and Dynamic Goernance for Combating Corruption: The Challenge for Indonesia. Bisnis \& Birokrasi Journal, 20(1). 
Kaufmann, D., \& Kraay, A. (2020). The Worldwide Governance Indicators. Retrieved from http://info.worldbank.org/governan ce/wgi/

Peraturan Menteri Pendayagunaan Aparatur Negara dan Reformasi Birokrasi Nomor 29 Tahun 2012 tentang Perubahan Rencana Kerja Strategis Tahun 2010 - 2014, (2012a).

Surat Edaran Menteri PAN dan RB Nomor 16 Tahun 2012 tentang Tata Cara Pengisian Jabatan Struktural yang Lowong Secara Terbuka di Lingkungan Instansi Pemerintah, (2012b).

Peraturan Menteri Pendayagunaan Aparatur Negara dan Reformasi Birokrasi Nomor 13 Tahun 2014 tentang Tata Cara Pengisian Jabatan Pimpinan Tinggi Secara Terbuka di Lingkungan Instansi Pemerintah, (2014).

Peraturan Menteri Pendayagunaan Aparatur Negara dan Reformasi Birokrasi Nomor 38 Tahun 2017 tentang Standar Kompetensi Jabatan Aparatur Sipil Negara, (2017).

KemenPAN-RB. (2018). Sejumlah Capaian Reformasi Birokrasi 20142018. Retrieved from https://www.menpan.go.id/site/beri ta-terkini/sejumlah-capaianreformasi-birokrasi-2014-2018

KemenPAN-RB. (2019). Rencana Strategis Kementerian PAN-RB. Jakarta Retrieved from https://kita.menpan.go.id/wpcontent/uploads/2019/11/KonsepRenstra-Kemenpan-2020-2024.pdf

Komarudin. (2012). Penataan Struktur Birokrasi: Kementerian dan
Lembaga Pemerintah Non

Kementerian. Jurnal

Pendayagunaan Aparatur Negara, II(II), 10-33. Retrieved from https://www.menpan.go.id/site/ema gz/jurnal/2012_Jurnal_Tahun_201 2.pdf.

Komisi Pemberantasan Korupsi. (2010). Integritas Sektor Publik Indonesia Tahun 2010. Retrieved from Jakarta:

https://acch.kpk.go.id/id/componen t/bdthemes_shortcodes/?view $=$ dow nload\&id=e79496b63a78a5c97bfe 9f5e078551

Komisi Pemberantasan Korupsi. (2018). Survei Penilaian Integritas: Laporan Ilmiah Gabungan 2018. Retrieved from Jakarta: https://www.kpk.go.id/images/01/L aporan-Ilmiah-Gabungan-SPI2018---Indonesia.pdf

Kuhlmann, S., Bogumil, J., \& Grohs, S. (2008). Evaluating Administrative Modernization in German Local Governments: Success or Failure of the "New Steering Model"? Public Administration Review, 68(5), 851863. Retrieved from https://onlinelibrary.wiley.com/doi/ abs/10.1111/j.15406210.2008.00927.x. doi:10.1111/j.15406210.2008.00927.x

McCourt, W. (2018). Towards "cognitively complex" problem-solving: Six models of public service reform. Development Policy Review, 36(S2), O748-O768. Retrieved from

https://onlinelibrary.wiley.com/doi/ abs/10.1111/dpr.12306. doi:10.1111/dpr.12306

McLeod, R. H. (2005). The struggle to regain effective government under democracy in Indonesia. Bulletin of Indonesian Economic Studies, 41(3), 367-386. 
Peraturan Menteri Negara Pendayagunaan Aparatur Negara dan Reformasi Birokrasi Nomor 20 Tahun 2010 tentang Road Map Reformasi Birokrasi 2010-2014, (2010).

Peraturan Menteri Negara Pendayagunaan Aparatur Negara dan Reformasi Birokrasi Nomor 11 Tahun 2015 tentang Road Map Reformasi Birokrasi 2015-2019, (2015).

Peraturan Menteri Negara Pendayagunaan Aparatur Negara dan Reformasi Birokrasi Nomor 25 Tahun 2020 tentang Road Map Reformasi Birokrasi 2020-2024, (2020).

Nurprojo, I. S. (2014). Merit System dan Politik Birokrasi di Era Otonomi Daerah. Civil Service Journal, 8(1 Juni).

Osborne, D., \& Gaebler, T. (1992). Reinventing Government: How the Entrepreneurial Spirit is Transforming the Public Sector: Addison-Wesley Publishing Company.

Park, S. (2019). Dusk for the pyramidshaped bureaucracy: examining the shape of the U.S. federal bureaucracy in the twenty first century. Quality \& Quantity, 53(3), 1565-1585. Retrieved from https://doi.org/10.1007/s11135018-0827-1. doi:10.1007/s11135018-0827-1

Polidano, C., \& Hulme, D. (1999). Public Management Reform in Developing Countries. Public Management: An International Journal of Research and Theory, 1(1), 121-132. Retrieved from https://doi.org/10.1080/147190378 00000007 . doi:10.1080/14719037800000007

Pollitt, C., \& Bouckaert, G. (2004). Public Management

Reform:
Comparative Analysis. New York: Oxford University Press.

Pollitt, C., \& Bouckaert, G. (2011). Public Management Reform: A Comparative Analysis-New Public Management, Governance, and the Neo-Weberian State (Third ed.). New York: Oxford University Press.

Prasojo, E. (2009). Reformasi Kedua: Melanjutkan Estafet Reformasi. Jakarta: Penerbit Salemba.

Prasojo, E., \& Holidin, D. (2018). Leadership and Public Sector Reform in Indonesia. In E. Berman (Ed.), Leadership and Public Sector Reform in Asia (pp. 53-83). Bingley: Emerald Publishing Limited.

Pratama, A. B. (2017). Bureaucracy reform deficit in indonesia: a cultural theory perspective. Journal of Public Administration and Governance, 7(3), 88-99.

Keputusan Presiden Republik Indonesia Nomor 87 Tahun 1999 tentang Rumpun Jabatan Fungsional Pegawai Negeri Sipil, (1999).

Undang-Undang Republik Indonesia Nomor 17 Tahun 2003 tentang Keuangan Negara, (2003).

Undang-Undang Republik Indonesia Nomor 17 Tahun 2007 tentang Rencana Pembangunan Jangka Panjang Nasional Tahun 2005-2025 (2007).

Peraturan Presiden Republik Indonesia Nomor 81 Tahun 2010 tentang Grand Design Reformasi Birokrasi 2010-2025, (2010).

Penjelasan atas Undang-Undang Republik Indonesia Nomor 23 Tahun 2014 tentang Pemerintahan Daerah, (2014).

Peraturan Pemerintah Republik Indonesia Nomor 11 Tahun 2017 tentang 
Manajemen Pegawai Negeri Sipil, (2017).

Rewansyah, A. (2011). Revitalisasi Manajemen Pegawai Negeri Sipil dalam Implementasi Reformasi Birokrasi di Indonesia. Jurnal Pendayagunaan Aparatur Negara, I(I), 109-138. Retrieved from https://www.menpan.go.id/site/ema gz/jurnal/2011_Jurnal_Tahun_201 1.pdf.

Saint-Martin, D. (1998). Management consultants, the state, and the politics of administrative reform in Britain and Canada. Administration \& Society, 30(5), 533-568.

Schiavo-Campo, S. (1996). Reforming the civil service. Finance and Development-English Edition, 33(3), 10-13.

Seddon, J., \& De Tommaso, G. (1999). Civil service reform and decentralization. Decentralization Briefing Notes. World Bank Institute Working Papers. Washington, DC: Banque mondiale.

Suleiman, E. N. (2013). Dismantling democratic states: Princeton University Press.

Sutiyono, W., Pramusinto, A., \& Prasojo, E. (2018). Introduction to the mini special issue: understanding governance in Indonesia. Policy Studies, 39(6), 581-588. Retrieved from

https://doi.org/10.1080/01442872.2 018.1530416 . doi:10.1080/01442872.2018.15304 16

The World Bank. (2009). Doing Business 2010: Reforming through difficult times. Retrieved from Washington, DC:

https://www.doingbusiness.org/con tent/dam/doingBusiness/media/An
nual-Reports/English/DB10FullReport.pdf

The World Bank. (2020). Doing Business 2020: Comparing Business Regulation in 190 Economies. Retrieved from Washington, DC: https://openknowledge.worldbank. org/bitstream/handle/10986/32436/ 9781464814402.pdf

Transparency International. (2010). Corruption Perceptions Index 2010. Retrieved from Berlin: http://files.transparency.org/content /download/132/531/2010_CPI_EN. pdf

Transparency International. (2020). Corruption Perceptions Index 2019. Retrieved from Berlin: https://files.transparency.org/conte nt/download/2428/14734/file/2019 _CPI_Report_EN.pdf

Turner, M. (2013). Summary Report of the Public Sector Governance Reform Evaluation. In: London: Oxford Policy Management Ltd (OPM).

Turner, M., Imbaruddin, A., \& Sutiyono, W. (2009). Human Resource Management: The Forgotten Dimension of Decentralisation in Indonesia. Bulletin of Indonesian Economic Studies, 45(2), 231-249. doi:10.1080/00074910903040336

Turner, M., Prasojo, E., \& Sumarwono, R. (2019). The challenge of reforming big bureaucracy in Indonesia. Policy Studies, 1-19. doi:10.1080/01442872.2019.17083 01

Ugyel, L. (2014). Explaining Hybridity in Public Administration: An Empirical Case of Bhutan's Civil Service. Public Administration and Development, 34(2), 109-122. Retrieved from https://onlinelibrary.wiley.com/doi/ $\mathrm{abs} / 10.1002 / \mathrm{pad} .1685$. doi:10.1002/pad.1685 
Jurnal Kebijakan Pembangunan Daerah, Vol.4, No.1, Juni 2020, Hal. 1 - 20

p-ISSN: 2597-4971, e-ISSN: 2685-0079

World Economic Forum. (2010). The Global Competitiveness Report 2010-2011. Retrieved from Geneva, Switzerland:

http://www3.weforum.org/docs/W EF_GlobalCompetitivenessReport 2010-11.pdf

World Economic Forum. (2017). The Global Competitiveness Report 2017-2018. Retrieved from Geneva, Switzerland:

http://www3.weforum.org/docs/GC R2017-

2018/05FullReport/TheGlobalCom petitivenessReport2017\%E2\%80\% 932018.pdf

World Economic Forum. (2019). The Global Competitiveness Report 2019. Retrieved from Geneva, Switzerland:

http://www3.weforum.org/docs/W EF TheGlobalCompetitivenessRep ort2019.pdf

Ylönen, M., \& Kuusela, H. (2019). Consultocracy and its discontents: A critical typology and a call for a research agenda. Governance, 32(2), 241-258. 